\title{
Fatty acid modification and membrane lipids
}

\author{
By Klaus W. J. WAHLE, Rowett Research Institute, Bucksburn, Aberdeen \\ $A B 29 S B$
}

This review focuses on the role of fatty acids and their effects on some of the physicochemical properties and biological functions of membranes. The consequences of the incorporation of structurally modified fatty acids of both endogenous and exogenous origin into such membranes are also discussed. Those who wish to gain a deeper insight into lipids and membranes are referred to the excellent reviews used as the reference basis for most of the background material.

\section{Biological membranes}

Membranes form the boundaries of cells and organelles and constitute the golgi apparatus and endoplasmic reticulum. They are essential for both the structural and metabolic organization within individual cells and for the integration of cellular activities within tissues and organs. Biological membranes exhibit a great diversity of physiological function which correlates with a similar diversity in composition and structure. They are not merely inert hydrophobic barriers but are highly selective, permeable barriers. They are intimately involved in the initiation, reception and transduction of neuro-endocrine stimuli, the transport of metabolites and ions and directly in the metabolism of the cell by means of their many membrane-bound enzymes (Raison, 1973; Marsh, 1975; Cullis \& DeKruijf, 1979; Thompson, 1980; Chapman, 1982).

\section{Membrane composition and structure}

Knowledge of the composition and structure of biological membranes is fundamental to the understanding of their diverse functions.

Plasma and intracellular membranes of mammalian cells generally constitute approximately $60 \%$ protein and $40 \%$ lipid by weight with o-10\% carbohydrate in the form of glycoprotein or glycolipid. The relative proportions of protein and lipid vary considerably between membranes and often reflect their different functions so that the metabolically active, inner mitochondrial membrane is relatively rich in protein whereas the insulating myelin membrane is rich in lipid (Marsh, I975; Thompson, 1980; Chapman, 1982).

Proteins are the functional components of biological membranes. They constitute the bound enzymes, neuro-endocrine receptors, and the various gates, channels and pumps responsible for the transport functions of the membrane. Their role is discussed below in relation to the current concepts of membrane structure and function. 
Lipid. The lipid component of biological membranes consists largely of different types of phospholipid and, depending on the membrane, varying amounts of cholesterol and glycolipid (van Deenen, 1965; Marsh, 1975; Thompson, 1980; Chapman, 1982). The major phospholipid classes in membranes are phosphatidylcholine and phosphatidylethanolamine, with significant contributions from phosphatidylserine, phosphatidylinositol, phosphatidylglycerol and sphingomyelin. Cardiolipin is present in mitochondrial membranes and various complex glycolipids are characteristic of neural membranes (van Deenen, 1965; Thompson, 1980; Chapman, I982).

The phospholipid composition of membranes is under genetic control and varies markedly between different tissues and organs within an individual animal. It also varies for the same tissues and organs between different species and is a specific characteristic of the membrane (van Deenen, 1965; Harrison \& Lunt, 1975; Marsh, 1975; Thompson, 1980; Chapman, 1982).

The phospholipids are amphiphiles in that they contain in their structure regions which are polar and hydrophilic and regions which are non-polar and hydrophobic, both of which are linked by a glycerol or sphingosine 'back-bone'. The hydrophilic regions are the head groups of the phospholipids, most commonly choline, ethanolamine, serine, inositol and glycerol, which vary in size, shape, polarity and charge. The hydrophobic elements are the constituent non-polar, aliphatic fatty acyl chains which can differ in both chain length and extent of unsaturation; various structurally modified fatty acids with trans double bonds and different side chains, such as methyl-branched fatty acids, also occur in phospholipids (van Deenen, 1965; Chapman, 1969, 1982; Marsh, 1975; Thompson, 1980 ). The distribution of saturated and unsaturated fatty acids in the phospholipid molecule is not random but is determined by the activity of specific acyltransferases during tissue synthesis of the molecule such that saturated fatty acids are generally esterified in the $\alpha$ position and unsaturated fatty acids in the $\beta$ position (McMurray \& McGee, 1972 ).

The hydroxyl group of cholesterol is also hydrophilic but the remaining steroid ring structure is hydrophobic (van Deenen, 1965; Marsh, 1975; Chapman, 1982).

The amphiphilic nature of phospholipids is such that in aqueous medium, above a certain critical concentration and temperature (van Deenen, I965; Sandermann, 1978) they will spontaneously form various micellar structures, including sheet-like bilayers, with their hydrophilic 'head groups' presented to the aqueous medium and their hydrophobic fatty acyl 'tails' tucked into the non-polar interior of the bilayer 'sandwich' (van Deenen, 1965; Marsh, 1975; Cullis \& DeKruijf, 1979; Chapman, I982). These phospholipid bilayers are stabilized by electrostatic and hydrogen-bonding interactions between the polar head groups and water and by van der Waal's forces between the hydrocarbon tails (van Deenen, 1965; Chapman, 1969, 1982). The polar head-group interactions are strongly influenced by their ionic environment (Träuble \& Eibl, 1974). Lipid bilayers have an inherent tendency to be extensive, to form closed ends and to be self-sealing (Chapman, 1969, 1982; Marsh, 1975; Thompson, 1980). 
This ability of phospholipids to form lipid bilayers is of fundamental importance for the currently most acceptable concept of membrane structure, although not the only one (Cullis \& DeKruijf, 1979), as proposed by Singer \& Nicholson (1972). Their fluid-mosaic model of a biological membrane depicts functional, often globular proteins floating like icebergs in a sea or matrix of 'fluid' phospholipids in a bilayer of mixed composition. This model incorporates the concept of a high degree of lateral mobility of the membrane components within the plane of the bilayer which facilitates protein-protein and protein-lipid interactions, an important feature in the understanding of membrane function and linked membrane-bound enzyme systems (Bakardjieva et al. 1979; Chapman, 1982).

Protein. The intrinsic proteins in the fluid-mosaic model penetrate the lipid bilayer matrix to different extents and some span the entire membrane in the vertical plane. The extent of penetration of the membrane proteins into the nonpolar, hydrophobic interior of the membrane bilayer depends on the extent to which non-polar, hydrophobic amino acids are presented to the exterior of the protein molecule (Capaldi \& Vanderkooi, 1972; Marsh, 1975; Chapman, 1982). Intrinsic proteins like phospholipids and, when present, cholesterol, are distributed asymmetrically between the lamellae of the membrane bilayer and this asymmetry is maintained by a lack of transmembrane diffusion (Rothman \& Lenard, 1977).

Membranes also possess peripheral or extrinsic proteins which do not penetrate the bilayer but are bound to the membrane by electrostatic and hydrogen-bond interactions (Marsh, 1975; Sandermann, 1978). Extrinsic proteins can be solubilized by relatively mild procedures whereas intrinsic proteins require detergent destruction of the protein-lipid bonds for solubilization (Rogers \& Strittmatter, 1973; Sandermann, 1978). Surface charge interactions between intrinsic proteins and phospholipid head groups help to stabilize the membrane (Träuble \& Eibl, 1974; Marsh, I975).

A cytoskeleton of protein has been observed on the inner face of certain plasma membranes such as erythrocytes and lymphoid cells (Jain \& Wagner, r980).

\section{Fluidity and thermotropic characteristics of phospholipid bilayers and membranes}

In recent years our knowledge of the physicochemical properties of phospholipid monolayers, bilayers, artificial membranes and biological membranes has increased dramatically due largely to the development of such sensitive techniques as nuclear magnetic resonance, electron spin resonance, wide angle $\mathrm{X}$-ray diffraction, differential scanning calorimetry and various spectroscopic methods (van Deenen, 1965; Chapman, 1969, 1982; Marsh, I975; Lee, 1977; Sandermann, 1978; Thompson, 1980). In particular, these techniques have been extensively used to investigate the thermotropic characteristics of lipid bilayers and membranes and have contributed greatly to our understanding of membrane structure and function.

At low temperatures, hydrated phospholipid bilayers exist as highly ordered gels with the $\mathrm{C}-\mathrm{C}$ bonds of their fatty acyl chains in the rigid trans conformation at an angle to the vertical plane which depends on the extent of hydration. This 
formation allows only slight torsional mobility and hence a tighter packing of the acyl chains is achieved. As the temperature is raised the molecular mobility of the fatty acyl chains gradually increases until, at a characteristic temperature, an abrupt thermal-phase transition occurs concomitantly with an increase in heat absorption and mobility of the fatty acyl chains. The bilayer then exists in a highly disordered, liquid-crystalline state and the $\mathrm{C}-\mathrm{C}$ bonds have a partially gauche conformation with an increase in torsional mobility; the bilayers are then in a 'fluid' state (van Deenen, 1965; Chapman, 1969, 1982; Marsh, 1975).

The temperature at which this reversible lipid-phase transition occurs is termed the phase transition temperature $\left(T_{t}\right)$ and is related to the fatty acid composition, the cholesterol content and polar head groups of the phospholipid bilayer (van Deenen, 1965; Thompson, 1980; Chapman, 1982). The $T_{\mathrm{t}}$ of pure phospholipid bilayers decreases with increasing unsaturation or decreasing chain length of the fatty acyl chains. The introduction of a cis double bond into the acyl chain produces a 'kink' in the chain which creates a steric hindrance to the tight packing and thereby allows a greater mobility of the acyl chains and a decrease in $T_{\mathrm{t}}$. Also, the shorter hydrocarbon chains interact less strongly than long ones and this again decreases the $T_{\mathrm{t}}$ (van Deenen, 1965; Chapman, 1969, I982; Marsh, 1975). The insertion of a methyl-branched-chain fatty acid into a phospholipid bilayer also produces a steric hindrance to the acyl-chain packing similar to that observed for cis double bonds and consequently this will lower the $T_{\mathrm{t}}$ (van Deenen, 1965; Chapman, 1969, 1982; Legendre et al. 1980). The mobility of successive methylene groups in the acyl chain increases with their distance from the glycerol backbone (Levine et al. 1972) and, even in bilayers and membranes which are in the gel phase, the central region of the bilayer structure (which corresponds to the terminal methyl ends of the acyl chains) is still in a highly mobile, liquid-crystalline state (Ranck et al. 1974). This explains why fatty acyl chains with methyl branches near the terminal methyl end of the chain do not increase the fluidity (or decrease $T_{t}$ ) of a membrane or bilayer whereas those with methyl branches in the centre of the chain do (Legendre et al. 1980) (see below). The C-C bonds of the phospholipid polar head groups also exhibit increased mobility with distance from the glycerol backbone (Levine et al. 1972). Differences in headgroup composition of phospholipids have a great effect on the $T_{\mathrm{t}}$ of the bilayer; pure phosphatidylcholine has a $T_{\mathrm{t}} 20^{\circ}$ lower than phosphatidylethanolamine when both contain the same fatty acyl chains (Thompson, 1980).

The addition of equimolar concentrations of cholesterol to phospholipid bilayers above their $T_{\mathrm{t}}$ increases both the rigidity of the methylene groups between $\mathrm{C}_{2}$ and $\mathrm{C}_{10}$ of the acyl chains and the $T_{\mathrm{t}}$ of the lipid. However, addition of cholesterol to bilayers below their $T_{\mathrm{t}}$ has the opposite effect and decreases the rigidity and $T_{\mathrm{t}}$ of the bilayers and thereby increases their fluidity. This is effected by the cholesterol preventing the close packing of the fatty acyl chains (van Deenen, 1965; Chapman, 1969, 1982; Sandermann, 1978).

The study of the physicochemical properties of pure phospholipid bilayers has greatly enhanced the understanding of biological membranes. However, lipid 
matrices of membranes are composed of a complex array of phospholipid species with a variety of fatty acyl chains and possibly differing amounts of cholesterol inclusions. Such mixed phospholipid bilayers exhibit a far more complex thermotropic behaviour than the simple bilayers. In a mixed phospholipid bilayer, individual phospholipid types will have different thermotropic characteristics depending on the composition of their fatty acyl chains and head groups. With a reduction in temperature the bilayer will contain regions or 'domains' of lipid in the gel phase co-existing with lipid in the liquid-crystalline phase. This system can best be described as a dynamic mosaic with the relative proportions depending, reversibly, on the temperature; at low temperatures the gel phase will predominate. The thermotropic behaviour of mixed phospholipids, like that of biological membranes is, therefore, triphasic; liquid-crystalline to mixed to gel phase (van Deenen, 1965; Marsh, 1975; DeGrip et al. 1979; Legendre et al. 1980; Chapman, 1982).

The temperature-dependent phase separation of mixed phospholipids of membranes into domains also influences the distribution of the intrinsic proteins which are generally excluded from the gel phase and segregate with the liquid-crystalline lipid. Protein segregation can influence the function of the membrane (DeGrip et al. 1979; Legendre et al. 1980).

Spin-label and fluorescent probe experiments have also revealed that some intrinsic proteins or membrane-bound enzymes are surrounded by a coat or annulus of lipid which has been immobilized by lipid-protein interactions. This 'boundary lipid' has a different $T_{t}$ from that of the bulk lipid and appears to be essential for the attainment of maximal activity of the enzymes (Overath \& Träuble, 1973; Stier \& Sackmann, 1973; Rogers \& Strittmatter, 1973, 1974). Many membrane-bound enzymes have what appears to be a specific requirement for phospholipid before they can express their full activity. This phospholipid is considered to be the boundary lipid which allows the protein molecule to achieve its most active conformation (Rogers \& Strittmatter, 1973, 1974; Sandermann, 1978; McMurchie \& Raison, 1979). However, the absolute specificity of this boundary lipid is questionable since a variety of phospholipids and indeed detergents can replace the initial annulus and thereby allow the enzyme proteins to attain their fully active conformation (Warren et al. 1974, 1975; Dean \& Tanford, 1977). Also, there is strong evidence for a rapid exchange between boundary lipid and bulk lipid (Cullis \& Grathwohl, 1977). However, the physical state or, more precisely, the fluidity of the lipid matrix or lipid annulus or both, does influence the functioning of the intrinsic proteins of the membrane.

\section{Influence of dietary fatty acids on membrane properties and function}

The importance of the fatty acid milieu in relation to the fluidity of membrane lipids and the consequence of changes in this fluidity on membrane function has been extensively investigated. Changes in $T_{t}$ have been correlated with both abrupt discontinuities in Arrhenius plots (reaction rate $v$. reciprocal of absolute 
temperature) of various membrane functions (Cronan \& Gelman, I 975; Amatruda \& Finch, 1979; Im et al. 1979; McMurchie \& Raison, 1979; Innis \& Clandinin, $198 \mathrm{r} b)$ and changes in the fatty acid composition of membrane phospholipids (Haeffner \& Privett, 1975; Overath et al. 1976; Gidwitz et al. 1980; Innis \& Clandinin, $198 \mathrm{r} a$ ).

Houslay et al. (1976) substantially altered the lipid (fatty acid) composition of plasma membranes isolated from rat liver by the inclusion of dioleoyl-, dimyristoyl- and dipalmitoyl-choline and found that the lipid $T_{\mathrm{t}}$ was greatest with dipalmitoyl-choline. These observations are similar to those reported for pure phospholipid bilayers. The $T_{\mathrm{t}}$ in the modified plasma membranes also correlated with the temperatures at which abrupt discontinuities in the Arrhenius plots of glucagon-stimulated adenyl cyclase activity was observed. However, the Arrhenius plot for the fluoride-stimulated adenyl cyclase activity remained linear, indicating that the lipid-phase transition occurred only in the one half of the bilayer which contained the hormone receptor and that fluidity in this lamella was important for receptor-enzyme coupling (Houslay et al. 1976). These observations also illustrate how phospholipid asymmetry between the lamellae of the membrane bilayer can influence membrane function.

The fatty acid composition of membrane phospholipids can be extensively modified in vivo by both dietary means and by intrinsic mechanisms such as desaturation reactions. Growing Escherichia coli mutants (unsaturated fatty acid auxotrophs) on a medium containing unsaturated fatty acids (Overath et al. 1976) or feeding rats (Raison, I973; Haeffner \& Privett, I975; Hammer \& Wills, I979; McMurchie \& Raison, 1979; Innis \& Clandinin, $198 \mathrm{r} a, b$ ) and sheep (McMurchie \& Raison, I979) on diets rich in polyunsaturated fatty acids (PUFA) was shown to increase the content of these fatty acids in a variety of membranes. These included endoplasmic reticulum (Hammer \& Wills, 1979), plasma membrane (King et al. I977; Im et al. 1979) and mitochondrial membranes (Raison, 1973; Haeffner \& Privett, I975; McMurchie \& Raison, 1979; Innis \& Clandinin, 1981 $a, b)$. The changes in the extent of membrane fatty acid unsaturation elicited the expected decreases in the $T_{\mathrm{t}}$ of membrane lipids which were consistent with an increase in membrane fluidity (McMurchie \& Raison, 1979; Im et al. 1979; Innis \& Clandinin, $1981 a, b)$. The phase transitions or phase separations of the membrane lipids also correlated with abrupt discontinuities in the slope of the Arrhenius plots of various membrane-associated functions. A decrease in the slope of an Arrhenius plot is often, but not always, related to an increase in the energy of activation of a particular function (Raison, 1973; Im et al. r979; McMurchie \& Raison, 1979).

Membrane functions which are influenced by membrane fluidity include the insulin receptor sensitivity (Ginsberg et al. I982) and phenylalanine transport (Im et al. 1979) of plasma membranes from Ehrlich ascites cells; the succinate oxidase activity (Raison, I973; McMurchie \& Raison, I979) and ATPase-catalyzed exchange reaction between ATP and [ $\left.{ }^{32} \mathrm{P}\right]$ phosphatidylinositol (Innis \& Clandinin, I $98 \mathrm{I} b$ ) of inner mitochondrial membranes and the transport of hexoses across bacterial membranes (Overath et al. 1976; Legendre et al. 1980). The abolition of 
discontinuities in Arrhenius plots of membrane-bound enzyme activities by detergent treatment (solubilization) and the lack of such discontinuities in reactions catalyzed by soluble enzymes (Raison, 1973; Stier \& Sackmann, I973; McMurchie \& Raison, 1979) is further evidence that a change in the physical state of membrane lipids with alterations in temperature is related, at least in part, to the observed modulation of membrane-bound enzyme activity. The temperature at which the phase transition of membrane lipids and the discontinuities of the Arrhenius plots occur are not necessarily the same and depend on the position of the probe in the lipid matrix (Cullis \& DeKruijf, 1979).

The rapidity with which dietary fatty acids can influence membrane composition and function has been demonstrated by Innis \& Clandinin $(1981 a, b)$. These workers fed rats on diets rich in PUFA (soya-bean oil) or monoenoic fatty acids (rapeseed oil) in a cross-over experiment where groups of animals were fed on one diet for $11-12 d$, then switched to the second diet for a similar period of time and finally switched back to the first diet for $11-12 \mathrm{~d}$. These changes in diet produced rapid and reversible changes in the fatty acid composition of the phospholipids from the inner membranes of mitochondria, taken from cardiac tissue, which correlated with the fatty acids of the dietary lipid. In parallel to these compositional changes, rapid and reversible alterations in $T_{\mathrm{t}}$ occurred which also correlated with marked modulation of the kinetic properties of the mitochondrial ATPase exchange reaction. Thus, the PUFA diet increased the proportion of $18: 2$ fatty acids in the membrane, decreased $T_{\mathrm{t}}$ and enhanced the enzyme activity. $A$ rapid change in lipid composition of membranes is in agreement with the short half-lives observed for fatty acyl components which exhibit turnovers independent of the entire phospholipid molecule (Landriscina et al. 1976). It is evident that the fatty acid composition and physicochemical properties of membranes, particularly the thermotropic characteristics, are not controlled rigidly in situ but can be continually modified according to the profile of fatty acids which are available for incorporation into membrane lipids.

Although straight-chain saturated acids and cis-unsaturated fatty acids of varying length and extent of unsaturation are the most commonly available for incorporation into membrane phospholipids, particularly in mammalian tissues, structurally modified fatty acids with isomeric trans double bonds (Brisson, 1981 ) or methyl (Duncan et al. 1974) and even ethyl (Smith \& Calder, 1979) side chains can also be found in membrane phospholipids.

Fatty acids with trans double bonds are generally only minor components of most naturally occurring lipids. They occur at a concentration of $5-10 \%$ in beef fat and $2-8 \%$ in milk, but may increase to $20 \%$ in milk from cows fed on milk-fatdepressing diets (Storry \& Rook, I965). However, they may constitute up to $50 \%$ of the fatty acids of commercially hydrogenated vegetable and fish oils, although this figure varies greatly between different products (Brisson, $198 \mathrm{r}$ ). When given to rats, trans-fatty acids are incorporated into both phospholipids and neutral lipids of various tissues, including nervous tissue (Høy \& Hølmer, 1979; ReichwaldHacker et al. 1979; Ohlrogge et al. 1982). In humans, however, trans-fatty acids 
are found mainly in the neutral lipids of liver, heart, erythrocytes and plasma (Ohlrogge et al. 1982).

The specific fatty acyl transferases of mammalian tissues which are responsible for phospholipid synthesis (McMurray \& McGee, 1972), esterify the trans-fatty acid in the $\alpha$ position of the glycerol moiety thereby treating it as if it were a saturated fatty acid. The incorporation of trans-fatty acids rather than cis-isomers into membrane phospholipids, as in phospholipid bilayers and bacterial membranes, results in a reduction in membrane fluidity but the fluidity is still somewhat greater than that observed with fully saturated fatty acids (van Deenen, 1965; Overath et al. 1976; Tsao \& Lands, 1980). The incorporation of trans-fatty acids into phospholipids of mammalian membranes could thus influence the temperature-related modulation of membrane-bound reactions in a manner similar to their effect in membranes of $E$. coli (Overath et al. 1976).

Fatty acids with one or more methyl branch in the hydrocarbon chain are major components of bacterial membrane lipids (Haest et al. 1974). They also occur as minor components $(\mathrm{I}-2 \%)$ in the tissue lipids of ruminants where they are present as iso- and anteiso-branched acids which are derived largely from rumen bacterial lipids (Garton, 1975). However, when sheep and goats, but not cattle, are fed on diets containing mainly grain, the branched-chain fatty acids (BCFA) of their depot fats are increased to $10-15 \%$ of total fatty acids. These BCFA form a complex mixture of varying chain length with differences in the number and position of the methyl branches in the hydrocarbon chain (Duncan et al. 1974; Smith et al. 1979). They have been derived by the incorporation of methylmalonyl$\mathrm{CoA}$, a product of propionate metabolism, into fatty acids synthesized de novo; methylmalonyl-CoA has been shown to compete with malonyl-CoA in the fatty acid synthetase reaction in ruminant tissues (Scaife et al. 1978; Wahle \& Paterson, 1979). The occurrence of methyl branching in fatty acyl chains present in phospholipid bilayers introduces a steric hindrance to the tight packing of the acyl chains when their temperature is reduced; this lowers the $T_{\mathrm{t}}$ of the bilayer lipid (van Deenen, I965). The incorporation of BCFA into the phospholipids of biological membranes also reduces the $T_{\mathrm{t}}$ of the membrane lipids (Chapman, 1969). Legendre et al. (1980) used unsaturated fatty acid auxotrophs of $E$. coli, adapted to grow on BCFA, to investigate the effects of incorporation of these fatty acids into membrane phospholipids on the physical and functional properties of the bacterial membranes. By means of a wide-angle X-ray diffraction technique they observed that BCFA with a methyl branch in the middle region of the acyl chain decreased the $T_{\mathrm{t}}$ of membrane phospholipids and increased the fluidity and active transport of $\beta$-galactosides at a given temperature. The temperature at which the discontinuity in the Arrhenius plot of $\beta$-galactoside transport occurred also corresponded to the temperature of the lipid-phase transition. Physical and functional perturbations of the $E$. coli membrane are absent when the methyl branch is located near the terminal methyl end of the acyl chain, because this region remains in a highly disordered liquid-crystalline state even at low temperatures (Ranck et al. 1974). 
Little is known about the influence of BCFA on the physical and functional properties of mammalian membranes. The neurological abnormalities of patients with Refsums disease could be attributed to the accumulation of phytanic acid, a tetramethyl- $\mathrm{C}_{16}$ BCFA of plant origin, in myelin lipids (Lough, 1973), but thermotropic and functional studies have not been reported. Also, feeding rats on various proportions of a mixture of BCFA obtained from mutton fat did not result in discernible neurological disorders in these animals, although the BCFA were deposited in a variety of tissues including nerve lipids (Smith et al. 1982). BCFA have also been shown to accumulate in various tissues of vitamin $B_{12}$-deficient humans (Kishimoto et al. 1973), baboons (Garton et al. 1975) and neonatal sheep (Duncan et al. $198 \mathrm{I}$ ) but membrane studies are lacking.

\section{Endogenous modification of fatty acids}

The ability of exogenous, dietary fatty acids to rapidly and reversibly alter the lipid composition, physical properties and functions of membranes is evident from the previous section. However, the relative availability of saturated and unsaturated fatty acids for membrane phospholipid synthesis can be determined by the activity of membrane-bound desaturases. These enzymes catalyze the stereospecific removal of two hydrogen atoms from a pre-formed fatty acyl-CoA derivative, of either exogenous or endogenous origin, which results in the formation of a cis double bond (Gurr \& James, 1971; Jeffcoat, 1979); the enzymes are prefixed according to the position on the acyl chain from which they remove $\mathrm{H}$ atoms e.g. $\Delta 9, \Delta 6, \Delta_{5}$ and $\Delta_{4}$. Pugh \& Kates (1977) reported the direct desaturation of eicosatrienoyl lecithin to arachidonyl lecithin in rat liver showing that the acyl-CoA is not always the required precursor for desaturation.

The desaturase enzymes are tightly bound to the endoplasmic reticulum of the cell as intrinsic proteins (Rogers \& Strittmatter, 1973, 1974; Strittmatter \& Rogers, 1975; Holloway \& Holloway, 1975, 1977). They have an obligatory requirement for molecular oxygen, an electron donor (NADH or NADPH) and a short electron transport chain which consists of NADH-cytochrome $c$ reductase and cytochrome $b_{5}$. Electrons are passed from the donor by way of the reductase and cytochrome $b_{5}$ to the terminal desaturase protein which, in the reduced state, will react with molecular oxygen and the acyl-CoA substrate to form the product with a cis double bond (Oshino et al. 1966; Oshino \& Sato, 1972; Oshino \& Omura, 1973).

Extraction of lipid from microsomal preparations revealed a lipid requirement for the expression of full activity by the desaturase proteins and their electron transport proteins (Jones et al. 1969; Rogers \& Strittmatter, 1973, 1974; Safford et al. 1975). Evidence that membrane fluidity can influence desaturase activity is, however, equivocal. Holloway \& Holloway (1975, 1977) concluded that enzyme activity was not influenced by membrane fluidity. Rogers \& Strittmatter (1974) and Strittmatter \& Rogers (1975) on the other hand demonstrated that the thermotropic behaviour of endoplasmic reticular membrane influenced the phase separation and mobility of the cytochrome $b_{s}$ and NADH-cytochrome $c$ reductase 
proteins, thereby implying an effect of membrane fluidity on desaturase activity.

Both nutritional and hormonal changes greatly influence Jesaturase activity in animal tissues (Gellhorn \& Benjamin, 1965; Mercuri et al. 1967; Uchiyama, 1967; Inkpen et al. 1969; Castuma et al. 1972; DeGomez-Dumm et al. 1975, 1976; Chen \& Hoch, 1977; Jeffcoat, 1979). Food deprivation decreases the activity of both $\Delta 9$ and $\Delta 6$ desaturase enzymes and induction of $\Delta_{9}$ activity is most responsive to carbohydrate refeeding, whereas $\Delta 6$ is most responsive to protein refeeding; the latter can be suppressed by glucagon or dibutyryl-cAMP (DeGomez-Dumm et al. 1975, 1976). Hormones have been shown to influence the activity of $\Delta 9-, \Delta 6-$ and $\Delta_{5}$-desaturases differently (DeGomez-Dumm et al. 1975, 1976).

Chen \& Hoch (1977) observed that hypothyroidism in rats reduces the desaturase activity of microsomal preparations and also the fluidity of the inner mitochondrial membrane; mitochondrial phospholipids are largely of endoplasmic reticular origin, only cardiolipin is exclusively of mitochondrial origin (Innis \& Clandinin, $198 \mathrm{r} a$ ). The decreased membrane fluidity correlated with a reduction in oxidative phosphorylation. These workers showed that the abnormalities resulting from hypothyroidism and influencing desaturase activity could be rectified by thyroxine administration. These observations illustrate the effect of hormones on desaturase activity and consequently membrane fluidity and function.

Dietary PUFA, particularly those of the $\omega 6$ series like linoleic and arachidonic acids, markedly inhibit the activities of the $\Delta 9$ - and $\Delta 6$-desaturases respectively (Brenner \& Peluffo, 1966; Inkpen et al. 1969; Du \& Kruger, 1972; Wahle \& Radcliffe, 1977; Jeffcoat \& James, 1978). The mechanism of this inhibition is not clear but could be due to the formation of a product which influences the synthesis of desaturase protein at the level of transcription, as has been postulated for a similar inhibition of fatty acid synthetase by arachidonic acid (Flick et al. 1977). The need to supply unsaturated fatty acids by synthesis de novo for maintenance of membrane fluidity would not exist in the presence of dietary PUFA.

Isomeric trans-fatty acids also inhibit $\Delta 9-$ and $\Delta 6$-desaturase activities in various tissues when given to rats (Mahfouz et al. 1980; Cook, 1981; Shimp et al. 1982 ) or added to cow mammary microsomal preparations in vitro (K. W. J. Wahle and J. M. Elliot, unpublished results). As mentioned previously, trans-fatty acids in membrane phospholipids reduce membrane fluidity when compared with cisisomers. Their inhibitory effect on tissue desaturase activity would therefore serve only to further decrease membrane fluidity.

Feeding rats on a diet containing $5 \%$ by weight of a mixture of BCFA obtained from sheep adipose tissue (see above) results in a $50 \%$ inhibition of $\Delta_{9}$-desaturase activity in hepatic microsomes when compared with microsomes from rats given $5 \%$ palmitic acid (Wahle \& Hare, 1982). The inhibition does not appear to be due to any effect on membrane lipids since the $\omega$-hydroxylation of fatty acids, a membrane-bound $\mathrm{P}_{45} \mathrm{O}$-dependent reaction, is not influenced by the BCFA diet. The soluble hepatic fatty acid synthetase is also unaffected by the dietary BCFA. These observations suggest that the inhibition of $\Delta 9$-desaturase activity by BCFA is a specific effect of the fatty acids on the enzyme protein (Wahle \& Hare, 1982). 
Brett et al. (1971) found that fatty acids with a methyl branch in the middle of the acyl chain are not desaturated by the $\Delta \boldsymbol{g}$-desaturase of rat liver microsomes and this is regarded to be the consequence of steric hindrance by the methyl branch which prevents the fatty acid substrate from attaching to the active site of the enzyme. These workers did not consider the possibility that BCFA might be competitive inhibitors of the desaturase reaction. However, the observations of Legendre et al. ( 1980 ), showing that BCFA with a methyl branch in the middle of the acyl chain gave rise to maximal lipid perturbation when incorporated into $E$. coli membrane lipids, and the possibility that the membrane-bound desaturase enzymes may be susceptible to such lipid perturbations (Strittmatter \& Rogers, 1975), suggests that an indirect membrane effect of BCFA as modulators of desaturase activity cannot be precluded.

\section{Influence of metal ions on desaturase activity}

Copper sulphate, at the level of $250 \mathrm{mg} / \mathrm{kg}$ dry matter in the diet of pigs, increases tissue $\Delta 9$-desaturase activity (Ho \& Elliott, 1973; Thompson et al. 1973). However, $\mathrm{Cu}$ supplementation also increases the food intake of pigs and this alone could have enhanced $\Delta 9$-desaturase activity. Wahle \& Davies (1975) found that hepatic $\Delta 9$-desaturase activity was greatly reduced in Cu-deficient rats compared with pair-fed controls. Thus the $\mathrm{Cu}$ status of an animal affects its capacity to desaturate fatty acids and as a consequence membrane-lipid abnormalities could arise. Wahle \& Davies (1975, 1977) postulated that the Cu effect could manifest itself at the level of the electron transport chain, since the redox potential of $\mathrm{Cu}$ proteins made them ideal candidates for terminal components of such chains which were required to interact with molecular oxygen. The possibility that divalent $\mathrm{Cu}$ exerts its effect at the level of the phospholipid head groups of membrane lipids (Träuble \& Eibl, 1974) cannot be ruled out. Cu also tends to increase the peroxidation of membrane lipids (Wills, 1965) and their labilization (Chvapil, 1973). Microsomal fatty acid peroxidation is known to cause an increase in the order of the phospholipid acyl chains and thereby decrease membrane fluidity (Eichenberger et al. 1982).

$\mathrm{Zn}$ has been implicated as an important factor in the regulation of essential fatty acid (EFA) metabolism, notably those PUFA of the $\omega 6$ and $\omega_{3}$ series which have physiological activity (Cunnane, 1982). Linoleic acid increases abnormally in EFAsupplemented, $\mathrm{Zn}$-deficient rats and this has led to the suggestion that $\Delta 6$ desaturase activity is impaired in $\mathrm{Zn}$ deficiency (Cunnane et al. $\mathrm{I} 98 \mathrm{I}$; Cunnane, 1982). However, the $\Delta 6$-desaturation of $\left[\mathrm{I}^{14} \mathrm{C}\right]$ linoleic acid was found to be enhanced rather than impaired in mammary microsomes and uterine homogenates of $\mathrm{Zn}$-deficient, compared with $\mathrm{Zn}$-adequate, lactating rats (Cunnane \& Wahle, $198 \mathrm{r} a, b)$. The $\mathrm{Zn}$ deficiency did not influence hepatic microsomal $\Delta 6$-desaturase activity (Cunnane $\&$ Wahle, $198 \mathrm{r} b$ ). It would seem, therefore, that $\mathrm{Zn}$ deficiency influences $\Delta 6$-desaturase differently, for unknown reasons, in the tissues investigated. Microsomal $\Delta_{9}$-desaturase activity was increased by more than $200 \%$ in the livers of $\mathrm{Zn}$-deficient compared with control rats (Clejan et al. 1981). Similarly, 
$\Delta 6-$ and $\Delta_{5}$-desaturase activity was decreased in microsomes from $\mathrm{Zn}$-deficient rat testes (Clejan et al. 1982). These authors reported marked changes in microsomal lipids and postulated that $\mathrm{Zn}$ deficiency alters the fluidity of microsomal membranes from liver, testes and small intestine. $\mathrm{Zn}$ is capable of preventing peroxidation of liver membrane lipids and has been shown to have a stabilizing effect on lysosomal membranes (Chvapil, 1973; Bettger et al. 1978).

$\mathrm{Zn}$ and $\mathrm{Cu}$ appear, therefore, to have opposite effects on lipid peroxidation and membrane stability (Cunnane, 1982). For a review of the influences of $\mathrm{Cu}$ and $\mathrm{Zn}$ on EFA and prostaglandin metabolism the reader is referred to Cunnane (1982).

\section{The physiological significance of lipid-phase transitions in homeotherms in vivo}

The preceeding sections have concentrated on the role of fatty acids in determining the physical properties and functions of membranes and have emphasized how changing the membrane fatty acid composition, by dietary means or by intrinsic modification of preformed fatty acids, can affect these characteristics. Most of the changes in membrane function have been observed at temperatures well below the physiological temperature of homeotherms. Decreasing the body temperature to any significant extent in homeotherms (other than hibernators) tends to be an irreversible process. Indeed, poikilothermic and hibernating animals maintain the fluidity of their membranes by increasing the unsaturation of the phospholipid acyl chains to such an extent that phase transitions do not occur until the temperature falls well below $0^{\circ}$ and Arrhenius plots of membrane-bound enzymes do not exhibit discontinuities in the range ${ }^{0}-40^{\circ}$ (Raison, 1973). In homeotherms there is a temperature gradient from the body core to the peripheries and it is conceivable that short-term cooling could influence membrane fluidity and function in these peripheral regions, but animals would adapt their membrane composition to compensate for long-term cooling. This is illustrated by the greatly increased unsaturation of tissue lipids from the ears and lower legs of sheep when compared with subcutaneous (unshorn) regions (Duncan \& Garton, 1967 ).

Even at normal body temperature the extent of fluidity of the bulk lipid and of the annular lipid will presumably be related to the phospholipid head groups, concentration of cholesterol, lipid immobilization by proteins and the extent of unsaturation and chain length of the fatty-acyl chains. The influence of relatively minor changes in the fluidity of bulk or annular lipid on the function of specific membrane proteins merits investigation. Träuble \& Eibl (1974) found that changes in the ionic environment such as alterations in $\mathrm{pH}$ and concentrations of monovalent $\left(\mathrm{Li}^{+}, \mathrm{Na}^{+}, \mathrm{K}^{+}\right)$and divalent $\left(\mathrm{Mg}^{2+}, \mathrm{Ca}^{2+}\right)$ cations have marked effects on the gel-liquid crystalline state of phospholipid bilayers at constant temperature. Increased $\mathrm{pH}$ and monovalent cations reduce the transition temperature (fluidize the bilayer) whilst divalent cations have the opposite effect. Rather small changes in $\mathrm{pH}$ and ionic environment induce gross alterations in bilayer structure. It is conceivable, therefore, that certain proteins in biological membranes in vivo are surrounded by specific annular lipids, the structure of which is sensitive to local 
changes in ionic environment and that such structural alterations can influence the function of the particular protein.

In support of this suggestion, Buhr et al. (1979) and Carlson et al. (1982) have shown that in microsomal membranes prepared from rat and bovine corpora lutea (CL) removed at midcycle, the membrane lipids are in the fluid, liquid-crystalline state, whereas those from regressing luteal tissue revealed a phase transition in which a portion of the lipid bilayer was in the gel phase at body temperature. Coincident with the physical change in membrane lipids the authors observed a decline in CL function as evidenced by a decrease in plasma progesterone. Treatment of cows in midcycle with prostaglandin $F_{2 \alpha}\left(P_{G F} F_{2 \alpha}\right)$ elicited the same response in the phase transition of the membrane lipids and on plasma progesterone concentrations as spontaneous regression of the CL. A reduction in gonadotropin binding after $\mathrm{PGF}_{2 \alpha}$ treatment has been reported (Carlson et al. I982) suggesting that the ensuing luteolysis may be due to the loss of recognition of tropic hormone. These observations indicate a possible influence of PGF ${ }_{2 \alpha}$ on membrane structure and function in vivo.

From these observations it would appear that gel-liquid crystalline phase transitions do occur in membrane lipids in vivo. The physiological factors which trigger these lipid-phase changes remain to be elucidated. It is conceivable that such changes in the physical characteristics of the lipid matrix could also have a modulating effect on membrane function as suggested by the impaired progesterone secretion in the regressing $\mathrm{CL}$, and that the fatty acid composition and the head groups of the membrane phospholipids would therefore play an important role in the regulation of membrane function.

The author would like to thank his colleagues, Dr G. A. Garton, F.R.S., Dr A. K. Lough and Mr C. R. A. Earl for their helpful discussions and comments.

\section{REFERENCES}

Amatruda, J. M. \& Finch, E. D. (1979). F. biol. Chem. 254, 26 r 9.

Bakardjieva, A., Galla, H. J. \& Helmreich, E. J. M. (1979). Biochemistry 18, 3016.

Bettger, W. J., Reeves, P. G. \& O'Dell, B. L. (1978). Proc. Soc. exp. Biol. Med. 158, 279.

Brenner, R. R. \& Peluffo, R. O. (1966). F. biol. Chem. 24I, 5213.

Brett, D., Howling, D., Morris, L. J. \& James, A. T. (1971). Arch. Biochem. Biophys. 143, 535.

Brisson, G. J. (I981). Lipids in Human Nutrition. An Appraisal of Some Dietary Concepts. Lancaster: MTP Press.

Buhr, M. M., Carlson, J. C. \& Thompson, J. E. (1979). Endocrinology 105, 1330.

Capaldi, R. A. \& Vanderkooi, G. (1972). Proc. natn. Acad. Sci., USA 69, 930.

Carlson, J. C., Buhr, M. M., Wentworth, R. \& Hansel, W. (1982). Endocrinology 11 10, 1472.

Castuma, J. C., Catala, A. \& Brenner, R. R. (1972). Y. Lipid Res. 13, 783.

Chapman, D. (1969). Lipids 4, 25 I.

Chapman, D. [editor] (1982). In Biological Membranes, vol. 4, p. 179. London and New York: Academic Press.

Chen, Y. D. I. \& Hoch, F. L. (1977). Arch. Biochem. Biophys. 181, 470.

Chvapil, M. (1973). Life Sci. 13, 104r. 
Clejan, S., Castro-Magana, M., Collipp, P. J., Jonas, E. \& Maddaiah, V. T. (rg82). Lipids 17, 129.

Clejan, S., Maddaiah, V. T., Castro-Magana, M. \& Collipp, P. J. (1981). Lipids I6, 454.

Cook, H. W. (198r). Lipids 16, 920.

Cronan, J. E. \& Gelman, E. P. (1975). Bacteriol. Rev. 39, 232.

Cullis, P. R. \& DeKruijf, B. (1979). Biochim. biophys. Acta 559, 399.

Cullis, P. R. \& Grathwohl, C. L. (1977). Biochim. biophys. Acta 471, 213.

Cunnane, S. C. (1982). Prog. Lipid Res. 21, 73.

Cunnane, S. C., Huang, Y. S., Horrobin, D. F. \& Davignon, J. (1981). Prog. Lipid Res. 20, 157.

Cunnane, S. C. \& Wahle, K. W. J. (1981a). Lipids 16, 771 .

Cunnane, S. C. \& Wahle, K. W. J. (1981b). Abstr. Proc. 12th Int. Congr. Nutr., San Diego. No. $54^{2}$, p. 97.

Dean, W. L. \& Tanford, C. (1977). F. biol. Chem. 252, 355 1.

DeGomez-Dumm, I. N. T., DeAlaniz, M. J. T. \& Brenner, R. R. (1975). F. Lipid Res. r6, 264.

DeGomez-Dumm, I. N. T., DeAlaniz, M. J. T. \& Brenner, R. R. (1976). F. Lipid Res. 17, 616.

DeGrip, W. J., Drenthe, E. H. S., Van Echteld, C. J. A., DeKruijf, B. \& Verkleij, A. J. (I979). Biochim. biophys. Acta 558, 33 O.

Du, J. T. \& Kruger, F. A. (1972). F. Nutr. 102, 1033.

Duncan, W. R. H. \& Garton, G. A. (1967). F. Sci. Fd Agric. 18, 99.

Duncan, W. R. H., Lough, A. K., Garton, G. A. \& Brooks, P. (I974). Lipids 9, 669.

Duncan, W. R. H., Morrison, E. R. \& Garton, G. A. (1981). Br. F. Nutr. 46, 337.

Eichenberger, K., Bohni, P., Winterhalter, K. H., Kawato, S. \& Richter, C. (I98z). FEBS Lett. $142,59$.

Flick, P. K., Chen, J. \& Vagelos, P. R. (1977). F. biol. Chem. 252, 4242.

Garton, G. A. (1975). Rep. Rowett Inst. 31, 124.

Garton, G. A., Scaife, J. R., Smith, A. \& Siddons, R. C. (1975). Lipids 10, 855.

Gellhorn, A. \& Benjamin, W. (1965). Ann. N.Y. Acad. Sci. 131, 344.

Gidwitz, S., Pessin, J. E., Weber, M. J., Glaser, M. \& Storm, D. R. (1980). Biochim. biophys. Acta 628, 263.

Ginsberg, B. H., Jabour, J. \& Spector, A. A. (1982). Biochim. biophys. Acta 690, 157.

Gurr, M. I. \& James, A. T. (1971). Lipid Biochemistry: An Introduction. London: Chapman $\&$ Hall.

Haeffner, E. W. \& Privett, O. S. (1975). Lipids 10, 75.

Haest, C. W. M., Verkleij, A. J., DeGier, J., Scheck, R., Ververgaert, P. H. J. T. \& van Deenen, L. L. M. (1974). Biochim. biophys. Acta 356, 17.

Hammer, C. T. \& Wills, E. D. (1979). Br. F. Nutr. $41,464$.

Harrison, R. \& Lunt, G. G. (1975). Biological Membranes. Their Structure and Function. New York: Blackie, John Wiley and Sons.

Ho, S. K. \& Elliot, J. I. (1973). Can. F. Anim. Sci. 53, 537.

Holloway, C. T. \& Holloway, P. W. (1975). Arch. Biochem. Biophys. 167, 496.

Holloway, C. T. \& Holloway, P. W. (1977). Lipids 12, 1025.

Houslay, M. D., Hesketh, T. R., Smith, G. A., Warren, G. B. \& Metcalfe, J. C. (1976). Biochim. biophys. Acta 436, 495 .

Høy, C. E. \& Hølmer, G. (1979). Lipids 14, 727.

Im, W. B., Deutchler, J. T. \& Spector, A. A. (1979). Lipids 14, 1003.

Inkpen, C. A., Harris, R. A. \& Quackenbusch, F. W. (1969). F. Lipid Res. 10, 277.

Innis, S. M. \& Clandinin, M. T. (1981a). Biochem. F. 193, 155.

Innis, S. M. \& Clandinin, M. T. (1981b). Biochem. f. 198, 167 .

Jain, M. K. \& Wagner, R. C. (1980). Introduction to Biological Membranes. New York: John Wiley.

Jeffcoat, R. (1977). Biochem. Soc. Trans. 5, 81 I.

Jeffcoat, R. (1979). Essays Biochem. x5, I.

Jeffcoat, R. \& James, A. T. (1978). FEBS Lett. 85, I 14.

Jones, P. D., Holloway, P. W., Peluffo, R. O. \& Wakil, S. J. (1969). F. biol. Chem. 244, 744.

King, M. E., Stavens, B. W. \& Spector, A. A. (1977). Biochemistry 16, 5280.

Kishimoto, Y., Williams, M. Moser, H. W., Hignite, C. \& Biemann, K. (1973). F. Lipid Res. 14,69 . 
Landriscina, C., Megli, F. M. \& Quagliariello, E. (1976). Lipids I I, 6 I.

Lee, A. G. (1977). Biochim. biophys. Acta 472, 285.

Legendre, S., Letellier, L. \& Schechter, E. (1980). Biochim. biophys. Acta 602, 491.

Levine, Y. K., Birdsall, N. J. M., Lee, A. G. \& Metcalfe, J. C. (I972). Biochemistry I I, I4I6.

Lough, A. K. (1973). Progr. Chem. Fats 14, I.

McMurchie, E. J. \& Raison, J. K. (1979). Biochim. biophys. Acta 554, 364.

McMurray, W. C. \& McGee, W. L. (1972). Ann. Rev. Biochem. 41, 129.

Mahfouz, M. M., Johnson, S. \& Holman, R. T. (1980). Lipids 15, 100.

Marsh, D. (1975). Essays Biochem. II, I39.

Mercuri, O., Peluffo, R. O. \& Brenner, R. R. (1967). Lipids 2, 284.

Muto, Y. \& Gibson, D. M. (1970). Biochem. biophys. Res. Commun. 38, 9.

Ohlrogge, J. B., Gulley, R. M. \& Emken, E. A. (1982). Lipids 17, 55 I.

Oshino, N., Imai, Y. \& Sato, R. (1966). Biochim. biophys. Acta 128, 13.

Oshino, N. \& Omura, T. (1973). Arch. Biochem. Biophys. 157, 395.

Oshino, N. \& Sato, R. (1972). Arch. Biochem. Biophys. 149, 369.

Overath, P., Thilo, L. \& Träuble, H. (1976). Trends Biochem. Sci. I, 186.

Overath, P. \& Träuble, H. (1973). Biochemistry 12, 2625.

Pugh, E. L. \& Kates, M. (1977). F. biol. Chem. 252, 68.

Raison, J. K. (1973). Symp. Soc. exp. Biol. 27, 485.

Ranck, J. L., Mateu, L., Sadler, D. M., Tardieu, A., Gulik-Krzywicki, T. \& Luzzati, V. (1974). F. molec. Biol. $85,249$.

Reichwald-Hacker, I., Grosse-Oetringhaus, S., Kiewitt, I. \& Mukherjee, K. D. (1979). Biochim. biophys. Acta 575, 327.

Rogers, M. J. \& Strittmatter, P. (1973). F. biol. Chem. 248, 800.

Rogers, M. J. \& Strittmatter, P. (1974). F. biol. Chem. 249, 895 .

Rothman, J. E. \& Lenard, J. (1977). Science 195, 743.

Safford, R., Jeffcoat, R. \& James, A. T. (1975). Biochim. biophys. Acta 409, 86.

Sandermann, H. (1978). Biochim. biophys. Acta $515,209$.

Scaife, J. R., Wahle, K. W. J. \& Garton, G. A. (1978). Biochem. F. 176, 799.

Shimp, J. L., Bruckner, G. \& Kinsella, J. E. (1982). F. Nutr. $112,722$.

Singer, S. J. \& Nicholson, G. L. (1972). Science $175,720$.

Smith, A. \& Calder, A. G. (1979). Biomed. Mass Spectrum. 6, 347.

Smith, A., Calder, A. G., Lough, A. K. \& Duncan, W. R. H. (1979). Lipids 14, 953.

Smith, A., Lough, A. K. \& Earl, C. R. A. (1982). F. Sci. Fd Agric. 33, 421.

Steck, T. L. (1974). J. Cell Biol. 62, 1.

Stier, A. \& Sackmann, E. (1973). Biochim. biophys. Acta 31 1, 400.

Storry, J. E. \& Rook, J. A. F. (1965). Br. Y. Nutr. 19, 101.

Strittmatter, P. \& Rogers, M. J. (1975). Proc. natn. Acad. Sci, USA 72, 2658.

Thompson, E. H., Allen, C. E. \& Meade, R. J. (1973). Y. Anim. Sci. 36, 868.

Thompson, G. A. (1980). The Regulation of Membrane Lipid Metabolism. Florida: CRC Press.

Träuble, H. \& Eibl, H. (1974). Proc. natn. Acad. Sci., USA 71, 214.

Tsao, Y-K. \& Lands, W. E. M. (1980). Science 207, 777.

Uchiyama, M., Nakagawa, M. \& Okui, S. (1967). J. Biochem., Tokyo 62, I.

van Deenen, L. L. M. (1965). Prog. Chem. Fats 8, 1.

Verkleij, A. J., Zwaal, R. F. A., Comfurias, P., Kastelijn, D. \& van Deenen, L. L. M. (1973). Biochim. biophys. Acta 323, 178.

Wahle, K. W. J. \& Davies, N. T. (1975). Br. f. Nutr. 34, 105.

Wahle, K. W. J. \& Davies, N. T. (1977). F. Sci. Fd Agric. 28, 43.

Wahle, K. W. J. \& Hare, W. R. (1982). Br. F. Nutr. 47, 61.

Wahle, K. W. J. \& Paterson, S. M. (1979). Int. Y. Biochem. 10, 433.

Wahle, K. W. J. \& Radcliffe, J. D. (1977). Lipids 12, 135.

Warren, G. B., Houslay, M. D., Metcalfe, J. C. \& Birdsall, N. J. M. (1975). Nature, Lond. $25,684$.

Warren, G. B., Toon, P. A., Birdsall, N. J. M., Lee, A. G. \& Metcalfe, J. C. (1974). Proc. natn. Acad. Sci., USA 71, 622.

Wills, E. D. (1965). Biochim. biophys. Acta 98, 238.

Printed in Great Britain 